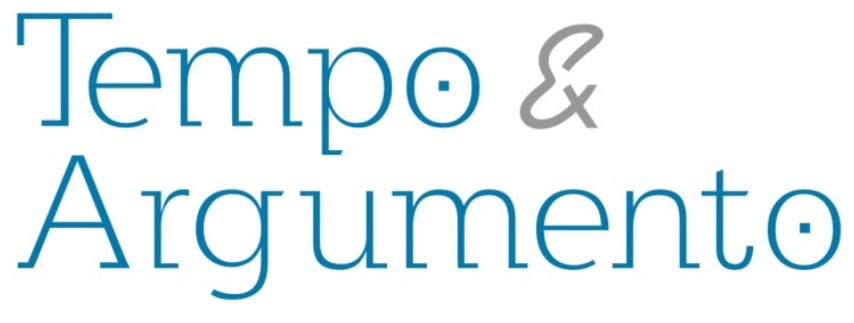

\title{
Escreviver o passado, cenaviver o presente: historiografia sobre cultura marginal no Piauí
}

\begin{abstract}
Resumo
O trabalho visa a refletir sobre o processo de constituição de uma historiografia sobre a cultura e a arte marginais no Piauí. Para tanto, procura discutir as maneiras como tal produção se configura confaz dentro e fora do ambiente acadêmico, no qual ganha uma maior visibilidade, tendo em vista a formatação de grupos e projetos de pesquisa dedicados ao seu estudo. Também pretende analisar de que forma a escrita historiográfica piauiense sobre o tema se relaciona com a que é produzida em âmbito a nível nacional, observando, especialmente, a inserção de autores locais em publicações coletivas de maior abrangência.
\end{abstract}

Palavras-chave: Historiografia. Cultura marginal. Piauí.

\section{Edwar de Alencar Castelo Branco} Doutor em História e Bolsista de Produtividade em Pesquisa do CNPq. Professor associado da

Universidade Federal do Piauí. edwar2005@uol.com.br

\section{Fábio Leonardo Castelo Branco Brito} Mestre em História. Professor substituto da Universidade Estadual do Piauí. fabioleobrito@hotmail.com

\section{Para citar este artigo: \\ CASTELO BRANCO, Edwar de Alencar; BRITO, Fábio Leonardo Castelo Branco. Escreviver o passado, cenaviver o presente: historiografia sobre cultura marginal no Piauí. Revista Tempo e Argumento, Florianópolis, v. 5, n.9, jan./jun. 2013. p. 66 - 85.}

\section{DOI: $10.5965 / 2175180305092013066$}

http://dx.doi.org/10.5965/2175180305092013066

\footnotetext{
* Este texto, parte dos estudos desenvolvidos no âmbito do MHB/UFPI, é resultado dos esforços de formatação da pesquisa "Torquato Neto e seus contemporâneos: vivências juvenis, experimentalismo e guerrilha semântica em Teresina", enquadrada na linha de pesquisa "História, Cultura e Arte", sob orientação do Prof. Dr. Edwar de Alencar Castelo Branco. O título faz referência aos neologismos construídos pelo poeta e cineasta marginal pernambucano Jomard Muniz de Brito, presentes em seu poema "Arrecifes do desejo".
} 


\section{Livewriting the past, sceneliving the present: the historiography about the marginal culture in Piauí}

\begin{abstract}
This paper attempts to cast reflections on the construction of a history about the culture and art in the marginal Piauí. In this analysis, discuss the ways in which such productions are shown inside and outside the academic environment in which gain greater visibility, in view of the formatting groups and research projects devoted to its study. It also intends to examine how the writing on the subject of Piauí historiography relates to that produced nationally, noting in particular the inclusion of local authors in collective publications with wider coverage.
\end{abstract}

Keywords: Historiography. Marginal culture.

Piauí.
A geração marginália despertou confusa e vazia com o televisor na sala os primeiros vestígios aportaram na cidade com os projetos de cinema, poesia e os gestos cheios de dicas de Torquato e não foram enterrados em novembro de setenta e dois com seus ossos no cemitério São José a nossa geração teve pouco tempo para mostrar as asas quebradas e alçar o vôo suicida dos anjos predestinados. (José Pereira Bezerra - Panfleto Poético/82) 
A produção sobre cultura e práticas culturais, no âmbito da escrita historiográfica brasileira, tem-se mostrado multifacetada, em parte em razão do debate travado entre autores de diferentes orientações teóricas, os quais traçam os direcionamentos da disciplina no ambiente acadêmico. Discutir cultura, em especial procurando ampliar sua perspectiva para, dessa forma, incluir nela concepções que vão desde as culturas populares - campo de abrangência alargado a partir das discussões sobre o seu conceito antropológico $^{1}$ - até as perspectivas pós-modernas permite ao historiador debater categorias teóricas diversas. Permite-Ihe percorrer temáticas ligadas tanto às culturas populares no Brasil (incluindo aí desde as discussões sobre registros, perdas de bens culturais, compilações de manifestações folclóricas presentes em Sílvio Romero e Câmara Cascudo $^{2}$ ) até as "culturas eXtremas" dos jovens intermináveis, traçando um perfil das condições culturais da juventude em um contexto de identidades múltiplas e fugidias ${ }^{3}$.

Dessa forma, faz-se necessário perceber, nas teias do discurso, o lugar de fala do historiador, no qual, concordando com Certeau (2000, p. 67), “toda interpretação histórica depende de um sistema de referências [...] que se infiltrando no trabalho de análise, organizando-o à sua revelia, remete à 'subjetividade' do autor”. É a partir dele que se faz possível remeter a práticas de análise e instrumentalização de uma pesquisa coerente com os objetivos formulados, posicionada dentro de um referencial teórico que se mostre apropriado, frente, tanto à variedade de conceitos, quanto à singularidade do objeto.

É, portanto, objetivo deste trabalho lançar luz sobre alguns tópicos de reflexão acerca da produção cultural piauiense, voltando especial atenção à produção de uma cultura marginal $^{4}$, sendo esta parte de um conjunto de práticas juvenis que, iniciadas em

\footnotetext{
${ }^{1}$ Para discussões mais amplas sobre a temática cultural, em especial a ampliação de sua vertente a partir de discussões acadêmicas, ver, dentre outras referências pertinentes: LARAIA, Roque de Barros. Cultura, um conceito antropológico; BURKE, Peter. O que é História Cultural?

${ }^{2}$ AYALA, Marcos; AYALA, Maria Ignez Novaes. Cultura popular no Brasil. São Paulo: Ática, 2002.

${ }^{3}$ CANEVACCI, Massimo. Culturas eXtremas: mutações juvenis nos corpos das metrópoles. Tradução: Alba Olmi. Rio de Janeiro: DP\&A, 2005.

4 A cultura marginal é entendida, no trabalho, como as práticas e produções artísticas de cunho experimental, feitas, em sua maioria, por jovens, e expressas em campos como a música, o cinema e a literatura. Para compreender tais produções e a aplicação do conceito, ver: COELHO, Frederico. Eu, brasileiro, confesso minha culpa e meu pecado: cultura marginal no Brasil das décadas de 1960 e 1970. Rio
} 
meados da década de 60, multiplicaram as concepções de linguagem e formas artísticas, expressas em manifestações literárias e cinematográficas. Pretende, dessa forma, levantar posicionamentos de autores que se dedicaram a escrever sobre o tema, remetendo às diferentes opiniões formuladas, no contexto social de um Piauí provinciano, mas em vias de modernização, que se observava, também, palco de ações direta ou indiretamente relacionadas com a tendência nacional.

\section{A cultura brasileira à luz da Marginália}

A discussão sobre cultura no Brasil, e sua inserção no contexto historiográfico, perpassa problemáticas ligadas aos vieses teóricos adotados pelos autores. Os debates orientados, levando em conta o caráter polissêmico de cada uma das vertentes analisadas, se confazem através de questões ligadas à escolha de temática feita pelo pesquisador, na qual se criam a pauta da diversidade e conflitos entre paradigmas teóricos e epistemológicos ${ }^{5}$. Pensar a cultura como parte de um amplo processo de busca da historiografia por um "ser" brasileiro, ainda trazendo à cena resquícios da problemática colonizadora, pode ser visto na fala de historiadores que abordam tal temática:

A cultura historiográfica brasileira recente, em paralelo a uma produção que extrapola limites nacionais e que diz respeito tanto a países colonizadores quanto colonizados - vem desenvolvendo um viés culturalista por excelência, pelo menos a partir da década de 80. Nesse diapasão, sujeitos novos e suas experiências, tidas pela historiografia centrada nos objetos institucionais como experiências sem história significando uma ausência de sentido, no limite compreendido como insólitas ou mesmo residuais, vêm para um cenário de conhecimento e legitimação social (QUEIROZ, 2001, p.37).

É possível compreender que a historiografia de viés cultural busca trazer à cena novos atores, uma maior multiplicidade de sujeitos, cujas tramas, sempre presentes, são reinventadas e introduzidas num contexto em que não tinham espaço. Leva-se, então, em

de Janeiro: Civilização Brasileira, 2010.

${ }^{5}$ Sobre a diversidade de paradigmas historiográficos na produção atual, ver: CARDOSO, Ciro Flamarion. História e Paradigmas Rivais. In: CARDOSO, Ciro Flamarion; VAINFAS, Ronaldo (Orgs.). Domínios da História: Ensaios de Teoria e Metodologia. Rio de Janeiro: Elsevier, 1997. p. 1-23. 
consideração a afirmativa defendida por José D’Assunção Barros (2011, p.18), de que todo campo disciplinar de estudo é histórico, tendo em vista que "não cessa de se atualizar, de se transformar, de se redefinir, de ser percebido de novas maneiras, de se afirmar com novas intensidades, de se reinserir no âmbito dos diversos campos de produção de conhecimento ou de práticas específicas".

É assim que a marginalidade ganha destaque no contexto da produção historiográfica nacional. Tendo em vista que a cultura marginal se manifesta enquanto produção destacada no final dos anos 1960 - mais precisamente com a participação de artistas baianos no Festival de Música Popular Brasileira, na TV Record, em 1967, e com o lançamento do disco Tropicalia ou Panis et Circensis, em 1968 -, sua discussão no contexto da História pode ser enquadrada enquanto história do tempo presente, o que acarreta, necessariamente, implicações éticas, ligadas ao distanciamento crítico do historiador em relação ao seu objeto ${ }^{6}$. Dessa maneira, cabe fazer uma cronologia da história nacional das produções sobre essa temática, com vistas a observar que a discussão ampliará seus debates, e chegará a pontos específicos do País.

$\mathrm{Na}$ busca de uma compreensão do tropicalismo, a partir das perspectivas de estética juvenil, a obra de Celso Favaretto, editada em 1979, confaz uma publicação que inicia um diálogo do tempo presente acerca do tema. Tropicália: alegoria, alegria se foca no conceito de que o tropicalismo não foi um movimento alienante em termos políticos, constituindo-se numa produção que manifestava onde havia a consciência do existir numa época de efervescência das ideias revolucionárias. As polissemias do movimento, observadas para além da "Passeata Contra as Guitarras Elétricas"7, encontravam na postura juvenil uma posição pertinente frente à realidade do País.

\footnotetext{
${ }^{6}$ Sobre a história do tempo presente, sua constituição enquanto disciplina, e seus debates ligados à ética do historiador, ver: BÉDARIDA, François. Tempo presente e presença da história. In: FERREIRA, Marieta de Morais; AMADO, Janaína. Usos \& abusos da História Oral. 6. ed. Rio de Janeiro: Editora da FGV, 2005. p. 219-229.

${ }^{7}$ Movimento ocorrido em 1967, contando com a participação de Elis Regina, Jair Rodrigues, Gilberto Gil, Edu Lobo, dentre outros. O objetivo era protestar contra a inserção das guitarras elétricas na Música Popular Brasileira, acreditando que uma "cópia" do modo de fazer música dos norte-americanos seria uma forma de "alienação" da música nacional.
} 
Corroborando com as colocações de Favaretto, Barreto Cordeiro Jr. analisa a Tropicália como um movimento de vanguarda artística, que guardava relação com uma forma particular de engajamento sociopolítico, ampliando os conceitos de participação e atuação da juventude. Segundo o autor:

Afirmamos acima que a atividade tropicalista não esteve engajada nas lutas político-sociais do Brasil, o que somente é verdadeiro se considerarmos como sendo "engajamento" apenas aqueles que seguem e acatam uma "linha diretiva partidária" ou os portadores de bandeiras tendenciosas de cunho ufanista. Igualmente, podemos ver no tropicalismo um compromisso para com a libertação das pulsações reprimidas, sugerindo uma recusa às normas comportamentais oficiais, além de propor uma mudança radical no campo das relações pessoais (CORDEIRO JR, 1989, p.9).

A maneira de expressar militância, não relacionada diretamente à participação político-partidária ou estudantil, condizia com um conhecimento de produções artísticas que embasariam teoricamente o movimento. As produções escritas acerca da cultura marginal denotam a presença de elementos do modernismo, enquanto manifestação artística. A obra Verdade Tropical, de Caetano Veloso, publicada em 1997, serve de exemplo de escrita sobre tais ideais, a partir de um ente que os praticava dos mesmos na época em questão. De acordo com o autor/fazedor de cultura alternativa, observavam-se no movimento conceitos ligados à antropofagia cultural, presentes no primeiro momento modernista no Brasil.

A idéia do canibalismo cultural servia-nos, aos tropicalistas, como uma luva. Estávamos "comendo" os Beatles e Jimi Hendrix. Nossas argumentações contra a atitude defensiva dos nacionalistas encontravam aqui uma formulação sucinta e exaustiva. Claro que passamos a aplicar com largueza e intensidade, mas não sem cuidados, e eu procurei, a cada passo, repensar os termos em que a adotamos (VELOSO, 1997, p. 248).

É possível observar, na literatura piauiense sobre a produção cultural da marginalidade, uma discussão que tem sublinhado a sua multiplicidade. O "ataque em diversas frentes" culturais se mostra presente na maioria dos textos que buscam caracterizar o movimento na contextualização de sua época. Tais olhares, no entanto, variam em termos de lugares de fala e vertentes teóricas, uma vez que se referem a diferentes campos do saber. Mesmo na academia, a cultura alternativa encontra discursos em campos como a 
História, a Literatura e a Sociologia. Cada um busca observar tal movimento, tendo como foco o olhar metodológico de sua disciplina ${ }^{8}$.

O polêmico e trágico poeta Torquato Neto, autor da letra da canção-manifesto do movimento tropicalista - Geléia Geral -, tem sido um dos mais recorrentes argumentos de intelectuais que se debruçam sobre a chamada "cena marginal". No âmbito dos estudos sobre a poética torquateana no contexto de sua estética underground, cujo principal argumento teria sido seu esforço para "destruir a linguagem e explodir com ela", podem ser observadas as obras de André Monteiro Guimarães Dias Pires e Paulo Andrade. Todas de caráter acadêmico, na área de Letras, versam sobre a produção poética de Torquato Neto na construção de uma nova composição literária. André Monteiro, em A ruptura do escorpião: ensaio sobre Torquato Neto e o mito da marginalidade (1999), trabalha a produção do poeta frente aos paradoxos culturais de tradição e ruptura. Já Paulo Andrade, em sua dissertação de mestrado, publicada sob o título de Torquato Neto: uma poética de estilhaços (2002), observa a construção de sua obra sob o olhar linguístico. Buscando, por seu turno, compreender a produção cinematográfica da marginalidade em uma perspectiva sociológica da apropriação de fragmentos, o maranhense Flávio Reis aborda, em Cenas Marginais (2005), a filmografia de Glauber Rocha, Roger Sganzerla e Julio Bressane, procurando analisar "uma marca profunda, a de um Brasil mais fragmentado, mesmo quando a temática dos filmes abordasse diretamente a construção de símbolos 'nacionais'” (2005, p. 10).

Da mesma maneira que começa a adquirir contornos de análise mais pormenorizada em pesquisas das Letras e Ciências Sociais, a temática passa a ganhar abordagens no campo teórico da História. A expressividade da cultura marginal na historiografia nordestina se torna visível com as discussões travadas por Durval Muniz de Albuquerque Júnior (1999, com reedição em 2011), em sua tese de doutorado, publicada sob o título $A$ invenção do Nordeste e outras artes, na qual problematiza a construção de uma "nordestinidade" a partir das produções artísticas criadoras de estereótipos do Nordeste. O autor, ao afirmar que o

\footnotetext{
8 Para apenas alguns exemplos, ver: BEZERRA, José. P. Anos 70 - por que essa lâmina nas palavras? Antiestética marginal \& geração mimeógrafo no Piauí. Teresina: Fundação Cultural Monsenhor Chaves, 1993; CORDEIRO JR, Barreto. Tropicalismo: fator de alienação ou de revisão crítica da realidade social? Teresina: Academia Piauiense de Letras, 1989; COUTO FILHO, Durvalino. Os caçadores de prosódias. Teresina: Projeto Petrônio Portela, 1994.
} 
Nordeste existe a partir de uma construção das linguagens e dos discursos acerca deles construções estas que partem de interesses das elites dominantes da região -, debate a formulação de uma concepção de Nordeste no Cinema Novo, em especial na obra de Glauber Rocha. Observando Glauber inserido numa perspectiva artística, chamada "estética da fome", o autor afirma:

Deus e o Diabo na Terra do $\mathrm{Sol}^{9}$ já se inicia com as imagens-clichê do sertão: a seca, o gado morto, o vaqueiro, o beato seguido por homens e mulheres que rezam pedindo chuva, que pedem o milagre para o Senhor da Boa Vida. A vida camponesa é representada pelo alheamento de Rosa e pelo delírio de Manuel. É uma vida parca, miserável, triste, vida de pessoas presas a relações de produção primitivas e a uma exploração violenta e discricionária. Este mundo estático é, de repente, movimentado pela revolta de Manuel, ao romper a subserviência do coronel, Manuel parece readquirir parte de sua humanidade (ALBUQUERQUE JÚNIOR, 2011, p. 314).

A leitura da obra de Albuquerque Júnior, obedecendo à sua contextualização, pode ser feita de duas (dentre várias) maneiras. Uma delas permite observar que o Cinema Novo, seguindo uma estética de experimentação nas artes, propunha um olhar crítico sobre o Nordeste a partir de uma visão da miséria, o que serviria de contrate em relação à realidade pregada pelo sistema político vigente à época. Por outro lado, serve como produção de novo estereótipo da realidade nordestina. Assim, mesmo considerando o Cinema Novo como uma distensão da proposta original dos marginais, a obra estabelece uma leitura da produção artística experimental, também como parte de um contexto de invenção do Nordeste de paradigmas preestabelecidos, e seguidos à risca por outras artes, estas mais "aceitas".

Poetas malditos, literatos e biógrafos: o acervo sobre cultura marginal no Piauí

O exposto corrobora a afirmação da existência de uma historiografia acerca das produções artístico-culturais locais, com estética experimental. As produções dos jovens no Nordeste se expressam em reinvenções das linguagens e na presentificação de

\footnotetext{
${ }^{8}$ Obra cinematográfica dirigida por Glauber Rocha, lançada em 1964, e considerada o marco inaugural do Cinema Novo no Brasil.
} 
elementos estruturais que marcam um hibridismo de estilos. A historiografia sobre o tema, no Piauí, observa as possibilidades de análise da cultura local, na qual a arte marginal se encontra inserida. Ainda sem maior inserção no bojo da academia, constituise de antologias poéticas e obras produzidas por interessados - escritores, historiadores e jornalistas - no resgate e manutenção de uma memória cultural do estado. Assim, a presença de "artísticas despóticos" em tal produção histórica é observada, principalmente, em trabalhos de cunho compilatório, com fortes traços de organização dos principais destaques da obra do autor/poeta em questão, bem como de sua biografia, seja ela em textos resumidos ou estendidos.

Dessa maneira, entende-se a necessidade de, fomentando a produção historiográfica, lançar um “outro olhar” sobre o Piauí que o Brasil, em tese, não costuma ver. De acordo com Claudete Dias, “a exemplo de vários estados brasileiros, o Piauí investe pouquíssimos recursos na produção do conhecimento histórico, artístico e cultural". A autora, reconhecendo que há pouco interesse dos historiadores de outros estados em pesquisar sobre o Piauí, defende que tal produção deve partir dos pesquisadores do estado (DIAS, 2003, p.215). No mesmo artigo, ressalta aspectos da cultura marginal no Piaú́, evidenciando elementos presentes em duas frentes dessa produção cultural: a literatura e o cinema. Aborda a poesia dos anos 1970, ocupando espaços em obras coletivas, jornais, revistas e suplementos alternativos, o que ficou caracterizado como "geração mimeógrafo" (Ibid., 224).

Uma das primeiras contribuições, em termos de leituras, para a compreensão dos movimentos artístico-literários dos anos 1970, se dá com a publicação, em 1993, de Anos 70: Por que essa lâmina nas palavras?, ensaio de José Pereira Bezerra, em sua atuação enquanto historiador. Na obra, faz referência à existência de uma primeira iniciativa de biografia mimeografada, dedicada à memória de Torquato Neto, sob o título "Tudo é Melhor que Nada", impresso em $1974^{10}$. Ao abordar questões de cunho político-social na época em questão, discute os limites e abrangências da arte transgressora, analisada como forma de manifestação de opiniões da juventude, formulando uma concepção que

\footnotetext{
9 BEZERRA, 1993:21. É possível perceber, na referência citada, a existência de uma historiografia sobre a "geração marginal" produzida pelos próprios mimeógrafos.
} 
admite a possibilidade de um pensar juvenil engajado, e não diretamente ligado às forças organizadas de mobilização estudantil. Em trechos do "Panfleto Poético", editado em 1982 e reproduzido na obra, fica clara a influência de Torquato Neto sobre a geração em questão, como colocado na epígrafe do presente artigo. Pode-se observar, na obra, um cunho de releitura das proposições de uma época, de reobservação, analítica ou compilatória, dos resultados de um momento histórico-cultural do País, reproduzido e ressignificado no Piauí:

O que resultou daqueles festivos anos insuportáveis? Pouca coisa, quase nada, mas o suficiente para evidenciar um momento de muita desinformação e manipulação, uma certa "idade média" cultural em que a produção cultural no Piauí era resultante de uma compulsão juvenil, de muita vitalidade, que buscava resistir ao sufoco (e os seus reflexos) imposto pelos instrumentos repressivos do regime militar pós-64 e pós68, que teve como contrapartida econômica o crescimento e o impulso modernizador do milagre brasileiro (BEZERRA, 1993, p.11).

O caráter biográfico e o desejo constante do resgate, presentes na historiografia piauiense já nos primeiros anos do século XXI, também ficam claros com a publicação, em 2001, da biografia e antologia acerca de Torquato Neto, resultado das pesquisas empreendidas pelo jornalista e literato piauiense Kenard Kruel, sob o título de Torquato Neto ou A Carne Seca é Servida. Ganhando uma segunda edição em 2008, a obra reúne, além do texto sobre a constituição familiar, vida e obra do poeta, um conjunto de sua produção poética e daquilo que viria a ser escrito sobre ele na imprensa local e nacional. Com maior importância, para a oficina dos historiadores, seja como fonte seja como obra problematizadora, a biografia e compilação sob análise constitui como parte de uma produção de base fundamental para a pesquisa relacionada a essa temática.

Estes estudos ganham maior profundidade quando se considera a obra de síntese, produzida por Luiz Romero Lima, acerca da construção de uma literatura piauiense. O autor reproduz uma fala de Paulo Machado, participante da geração de poetas "Pós-69" no Piauí, na qual este afirma:

No Piauí, a produção dos participantes da Geração Pós-69, que congrega as manifestações culturais da literatura, artes plásticas e gráficas, artes cênicas, música e arquitetura, tornou-se pública já nos primeiros anos da década de 70, quando ocorreram as veiculações de textos impressos, ou não, em mimeógrafos (jornais, revistas, livros, etc.) e nos suplementos 
encartados nos periódicos (principalmente O Dia, O Estado e Jornal da Manhã, os dois últimos já extintos) (MACHADO apud LIMA, 2003, p. 234).

Ainda considerando a escrita sob a égide da biografia e compilação de antologia, encontram-se referências à literatura marginal nos escritos de Zózimo Tavares, ao reunir, em uma obra, a produção compendiada de poetas piauienses que tiveram morte precoce. Ao lado de Alcides Freitas, Mário Faustino e Ramsés Ramos, Torquato Neto figura em Sociedade dos Poetas Trágicos como "um poeta que viveu pouco e intensamente todas as horas de seu fim" (TAVARES, 2004, p. 97). Seguindo a mesma lógica presente nas diversas outras obras aqui elencadas, o texto refere-se à criação cultural do poeta, inserindo-o em seu contexto sociopolítico.

Partindo do princípio de que os conceitos de história e historiografia se modificam ao longo do tempo, é necessário considerar que as obras de síntese elencadas contribuem para a constituição de um referencial de base para as pesquisas sobre o tema. Reunindo documentação primária e secundária, forjam possibilidades de leituras múltiplas, nas quais se tornam recorrentes aspectos das vivências e do cotidiano juvenis, o que será evidenciado também na produção acadêmica, em que, partindo de conceituações e leituras teóricas, a marginalidade ganha escopo de pesquisa embasada, formulada nos moldes da escrita erudita dos historiadores. Mas de que forma erudição e marginalidade podem conviver no mesmo texto?

\section{Um outro olhar: a marginalidade sob as lentes da academia}

O último recorte de análise do trabalho diz respeito à produção historiográfica do Piauí frente às novas possibilidades oriundas do advento da academia. Pautadas em princípios teóricos da Nova História Cultural ${ }^{11}$ e da Pós-Modernidade ${ }^{12}$, o olhar lançado à

\footnotetext{
${ }^{10}$ Perspectiva de abordagem na qual se tornam usuais, na escrita acadêmica piauiense, as leituras de Roger Chartier, em A História Cultural entre práticas e representações; da organização de artigos feita por Lynn Hunt, intitulada A Nova História Cultural, bem como os dois volumes de A invenção do cotidiano, resultado dos trabalhos de análise de Michel de Certeau, Luce Giard e Pierre Mayol.

${ }^{11}$ Destacam-se, nos textos referentes às práticas de subjetivação do sujeito histórico, na escrita historiográfica piauiense, as leituras de Stuart Hall, em A identidade cultural na pós-modernidade; Gilles Deleuze e Félix Guattari, nos volumes Mil Platôs, bem como na obra de Peter Pál Pelbart, A vertigem por um fio: políticas da subjetividade contemporânea.
} 
produção da cultura marginal no Piauí ganha força em monografias de conclusão de cursos de graduação, em dissertações de mestrado e em teses de doutorado. Tal afã de escrita histórica na universidade, como afirma Teresinha Queiroz (2006, p. 159-160), resulta também da obrigatoriedade, proposta pela reforma curricular, da construção de um trabalho de final do curso, fomentando o interesse pela pesquisa. Interesse que cresce com o surgimento do Programa de Pós-Graduação em História do Brasil da Universidade Federal do Piauí, nível de mestrado, fazendo crescer exponencialmente também a quantidade de grupos de pesquisa associados à instituição e ao programa em questão.

Referencia-se, em particular, Edwar de Alencar Castelo Branco, que, ao procurar compor academicamente e no âmbito da História uma contra-história da arte tropicalista, propõe em Todos os dias de Paupéria (2005), publicação resultante de sua tese de doutoramento, a participação de Torquato Neto no processo de invenção da Tropicália, processo que, segundo a obra, seria o marco inaugural da pós-modernidade no Brasil. Tendo como fonte de análise a década de 1960, o escritor busca abordar as possibilidades de um mundo novo que se apresenta, e de um Brasil que nele busca se inserir, construindo-se frente às novidades tecnológicas e ao boom de transformações comportamentais, as quais terão Torquato Neto e sua "geração" como principais expoentes.

Este texto tem a coragem de afirmar que estes anos significaram a chegada da pós-modernidade entre nós e sugerir o que isto significou: a emergência de um mundo cada vez mais mediado pelas maravilhas tecnológicas, um mundo marcado por novas experiências do tempo e do espaço, um tempo de corpos sensibilizados e acuados por novas e intensas experiências e experimentações, tempo de formação de novas sensibilidades, mundo novo onde os sentidos excitados por outras viagens e visagens requeriam a elaboração de novos códigos culturais, de novas linguagens para conseguir apreendê-las, dar a elas significado, dobrá-las com novas subjetividades (ALBUQUERQUE JÚNIOR, 2005, p.15).

Por "maravilhas tecnológicas", presentes no escopo da obra, entendem-se as novidades acarretadas com o cinema e a música popular em franco apogeu, bem como o advento da televisão e da telenovela. A cultura que viria a seguir, uma negação dos valores padronizados impostos pela realidade social, bem como da cultura de protesto, 
vista como politizada e panfletária, se caracterizaria por uma busca de "destruição da linguagem" em diversas frentes artísticas. O cinema, com bases hollywoodianas, é ressignificado com o advento do super-8 e as produções cinematográficas experimentais. A literatura do Grupo Meridiano passa a conviver com as "guerrilhas semânticas" da marginalidade pós-69.

Discutir novas estéticas artísticas, no âmbito da História, torna-se o motivador da produção de um conjunto de dissertações de mestrado, tendo como base pontos específicos das produções experimentais. Os autores, buscando capturar as subjetividades da cidade de Teresina através das lentes mimeografadas, fotográficas ou superoitistas, bem como dos ouvidos treinados para uma música que fugisse dos padrões do samba e da bossa nova, embarcam em pesquisas de posicionamentos tão marginais quanto seus objetos de pesquisa.

Defendida em 2007, a dissertação Curto-circuitos na sociedade disciplinar: super-8 e contestação juvenil em Teresina (1972-1985), de Frederico Osanan Amorim Lima, abre espaços na academia strictu sensu no Piauí para um olhar sobre a marginalidade cinematográfica. Centrado nas produções cinematográficas do chamado "espectro Torquato Neto" (anos 70) e do "grupo Mel de Abelha" (anos 80), o trabalho de pesquisa levou em conta o cinema enquanto tática juvenil, dando a ver elementos das condições de existência e aspectos comportamentais da juventude em questão. A marginalidade, na obra de Lima, pretende se autoconstruir em uma identidade, aspecto que será identificado a partir da construção do chamado sujeito pós-moderno, “conceptualizado por não ter uma identidade fixa, essencial ou permanente" (HALL, 1999, p. 12).

Diversos outros trabalhos, em nível de dissertação, mantêm a busca por uma identidade juvenil que quebrasse com padrões preestabelecidos. Dentre eles, é possível destacar as caracterizações de uma Teresina subjetivada pela fotografia, descrita por Demetrios Gomes Galvão, ${ }^{13}$ além das tensões culturais brasileiras vistas a partir da obra de Raul Seixas, numa perspectiva da estética da evolução, análise proposta por Emília

\footnotetext{
${ }^{12}$ GALVÃO, Demetrios Gomes. A fabricação de Teresinas: subjetividades e imagens fotográficas na experiência teresinense do Salão Municipal de Fotografia. 2008. Dissertação (Mestrado em História) Universidade Federal do Piaúi. Teresina.
} 
Saraiva Nery; ${ }^{14}$ ou, ainda, na construção de uma estética da existência, a partir da obra literária de Roberto Piva, observada por Reginaldo Sousa Chaves. ${ }^{15}$ Tal produção se encontraainda em aberto, uma vez que existe uma quantidade de trabalhos, nos âmbitos de graduação e pós-graduação, ligados à presente temática, tendo em vista ampliar seu debate.

A constituição de projetos e grupos de pesquisa também contribui para uma efetiva produção acadêmica, que aborde a multiplicidade de olhares sobre uma temática em questão. O projeto Guerrilha semântica: o cinema marginal no Piauí dos anos $1970^{16}$ veio atuar de maneira positiva para a veiculação de textos em publicações coletivas acerca do tema, analisando um conjunto de fotogramas táticos, a partir dos quais se observam elementos comportamentais da juventude desbundante piauiense. Em um deles, destacado da obra História e Historiografia (2006), é possível ler:

Os filmes aqui tratados, portanto, além de expandirem significativamente o conhecimento histórico que se tem da chamada "marginalia setenta", poderão demonstrar que as manifestações artísticas dos anos setenta - especialmente o cinema marginal - ainda oferecem um vasto campo de intervenção para a pesquisa histórica. Ainda que tais filmes constituam um conjunto de fontes pouco usuais nos estudos históricos, estes filmes, quando lidos em termos de seu capital simbólico, permitem analisar as formas como os seus produtores se relacionavam com o tempo, procurando inscrever sentidos sobre 0 mundo (CASTELO BRANCO \& MONTEIRO, 2006, p. 101).

Ainda no bojo dos projetos financiados, dos quais resultam subprodutos de pesquisa colaborativa, pode-se encontrar, no projeto Conciliábulos na praça: fanzines, cultura ordinária e literatura menor, um foco de reconstruções de valores marginais, impressos em obras juvenis que denotam múltiplas possibilidades de leitura. Dentre os artigos, publicados em obras coletivas, resultantes do projeto em questão, ou

\footnotetext{
${ }^{13}$ NERY, Emília Saraiva. Devires na música popular brasileira: Raul Seixas e as tensões culturais do Brasil nos anos 1970. 2008. Dissertação (Mestrado em História) - Universidade Federal do Piauí - Teresina.

${ }^{14}$ CHAVES, Reginaldo Sousa. Flanar pela Cidade-Sucata compondo uma estética da existência: Roberto Piva e seu devir literário experimental. 2010. Dissertação (Mestrado em História) - Universidade Federal do Piauí - Teresina:

${ }^{15}$ O projeto, coordenado pelo prof. dr. Edwar de Alencar Castelo Branco, contou com a participação de dois alunos: Frederico Osanan Amorim Lima (pós-graduação) e Jaislan Honório Monteiro (graduação), tendo como objetivo analisar as produções filmográficas em Teresina, indagando sobre a linguagem experimental dos jovens, sua estética, seus objetos e objetivos.
} 
relacionados com a temática, ganham destaque os intitulados Artistas diaspóricos, literatos desviados: fanzines, cultura ordinária e literatura menor, de Edwar de Alencar Castelo Branco, ${ }^{17}$ e Ressonâncias no meio do caminho e/ou no caminho do meio: a poética infame dos fanzines, de Demetrios Gomes Galvão. Em ambas as obras, que contam com a presença de autores atuantes em diversas regiões do País, dando à coletividade uma projeção nacional, é possível perceber os fanzines como resultado de uma estética juvenil, apropriadora de temáticas múltiplas, e instrumento de codificação, irradiador de discursos. Observando a perspectiva do autor, que vem denotar seus posicionamentos, é possível ler a busca, constante em todas as obras elencadas no artigo, por uma escrita que, além de tratar de um tema alternativo, seja libertadora e busque "desafinar” com as realidades e padronizações comuns à academia:

As paisagens contemporâneas têm se constituído por desenhos opacos e, por vezes, ilegíveis. Pintadas não mais por pincéis convencionais, mas compostas por colagens, intervenções e sobreposições. As imagens que têm estacionado sobre nossas retinas demarcam uma diferença entre a claridade das luzes e o embaralhamento dos signos que montam tais paisagens. As dimensões existenciais e as produções de sentido nos têm demonstrado que nos afastamos das grandes narrativas tranqüilizadoras, estáveis e centralizantes, tais como as ideologias políticas. Por outro lado, as discussões que subjugavam a cultura como um subproduto de estruturas políticas e econômicas perderam espaço para uma nova sensibilidade que compreende as produções econômicas e políticas pertencentes ao campo da cultura (GALVÃO, 2010, p. 81).

Percebe-se, na produção do autor, a presença de um posicionamento claro em termos historiográficos. Prega uma história cultural da sociedade, ao invés de uma história social da cultura. Dessa maneira, relaciona-se com a linguagem enquanto lugar de acontecimento da História, possibilitando "compreender que o cotidiano, longe de ser o lugar de opressão e do controle social, capaz de submeter e uniformizar as pessoas, é um lugar prenhe de interpretações e de desvios" (CASTELO BRANCO, 2009, p. 9).

Dessa maneira, corrobora as produções seguintes, ligadas ao grupo de pesquisa "História, Cultura e Subjetividade" ${ }^{18}$, donde resulta uma gama de trabalhos relacionados

\footnotetext{
${ }^{16}$ A pesquisa foi desenvolvida com o auxílio financeiro do CNPq, contando com a colaboração de Francisco Phelipe Cunha Paz, bolsista de iniciação científica do CNPq, e de Idelmar Gomes Cavalcante Júnior, à época, mestrando em História na UFPI.

${ }^{17}$ Grupo de pesquisa registrado no CNPq, tendo como sede a Universidade Federal do Piauí, e como líder o prof. dr. Edwar de Alencar Castelo Branco.
} 
à cultura marginal no Piauí, sob a ótica da diversidade de artes, posicionamentos políticos e sociais. Lançada em 2009, como resultado do trabalho coletivo do grupo de pesquisa em questão, a coletânea História, Cinema e outras imagens juvenis ganha destaque na produção recente sobre a historiografia marginal, mantendo a tradição de observar as criações juvenis, em especial nas décadas de 60 e 70, para além da ótica da política e opressão social, considerando os discursos como produtores de olhares e fundamentações do comportamento de grupos no contexto urbano. Dessa maneira, corroborando Mary Jane Spink e Rose Mary Frezza, que abordam o olhar múltiplo acerca do período, busca "adotar a concepção de que o conhecimento não é uma coisa que as pessoas possuem em suas cabeças, e sim algo que constroem juntas" (1999, p. 27, grifo das autoras).

\section{Considerações finais}

Se, ao observar a História, se parte de uma visão de que escrever o passado e viver o presente constituem ações contíguas, pode-se também perceber que o escrever e o viver agem sobre o homem como táticas de seu fazer cotidiano. A produção historiográfica, vista como processo de fornecer sentido ao cotidiano, construída sob os domínios da linguagem, processa a operação de localizar o homem como sujeito e objeto da História. Presentes nas atitudes, presentes também em sua maneira de co-operar sobre o tempo, os discursos emergem do texto e nele submergem, formatando visões, concebendo posicionamentos, desconstruindo paradigmas. Dessa maneira, concorda-se com Certeau, quando afirma:

Esses lapsos de vozes sem contexto, citações "obscenas" de corpos, ruídos à espera de uma linguagem, parecem certificar, por uma "desordem" secretamente referida a uma ordem desconhecida, que existe o outro. Mas ao mesmo tempo vão contando interminavelmente (é um murmúrio que jamais pára) a expectativa de uma impossível presença que muda em seu próprio corpo os vestígios que deixou. Essas citações de vozes são marcadas numa prosa cotidiana que não pode, em enunciados e em comportamentos, senão produzir seus efeitos (CERTEAU, 1994, p. 258). 
A construção de uma história da cultura marginal no Piauí é parte de uma necessidade de revisão nacional das discussões historiográficas. Observa-se, na revisão que se propõe o artigo em questão, a busca constante pela inserção dos artistas marginais no contexto de uma nova maneira de ver a arte: engajada, mas não panfletária; discursiva, mas não desligada do material; eminentemente contra, mas com um "contra" sempre alinhavado aos padrões de intolerância da sociedade vigente.

Nas buscas, por vozes dissonantes, por curto-circuitos operacionais na abordagem de poetas e cineastas, cabe dizer que aqueles que se dedicam à pesquisa sobre a temática da marginalidade artística produzem uma história obscena, impertinente, desordenada. Buscam compor o passado com os vestígios deixados pelos presentes, e que no presente ainda encontram lugar de fala. Processam-se em linhas analíticas do comportamental, e dedicam espaços às reminiscências, às lembranças e, principalmente, às manifestações naturais de uma marginalidade que não se decompõe com o passar do tempo, e que permanece viva no agir de seus (re)produtores.

\section{Referências}

ALBUQUERQUE JÚNIOR, Durval Muniz. O arteiro e o poeta. In: CASTELO BRANCO, Edwar de Alencar. Todos os dias de Paupéria: Torquato Neto e a invenção da Tropicália. São Paulo: Annablume, 2005. p. 15-18. . A invenção do Nordeste e outras artes. 5. ed. São Paulo: Cortez, 2011.

ANDRADE, Paulo. Torquato Neto: uma poética de estilhaços. São Paulo: Annablume/FAPESP, 2002.

AYALA, Marcos; AYALA, Maria Ignez Novaes. Cultura popular no Brasil. São Paulo: Ática, 2002.

BARROS, José D’Assunção. Teoria da História: 1. Princípios e fundamentos. Petrópolis: Vozes, 2011.

BÉDARIDA, François. Tempo presente e presença da história. In: FERREIRA, Marieta de Morais; AMADO, Janaína. Usos \& abusos da História Oral. 6. ed. Rio de Janeiro: Editora da FGV, 2005. p. 219-229. 
BEZERRA, José Pereira. Anos 70: por que essa lâmina nas palavras? (Antiestética marginal \& geração mimeógrafo no Piauí). Teresina: Fundação Cultural Monsenhor Chaves, 1993.

CANEVACCI, Massimo. Culturas eXtremas: mutações juvenis nos corpos das metrópoles. Tradução: Alba Olmi. Rio de Janeiro: DP\&A, 2005.

CASTELO BRANCO, Edwar de Alencar. Todos os dias de Paupéria: Torquato Neto e a invenção da Tropicália. São Paulo: Annablume, 2005.

; MONTEIRO, Jaislan Honório. Fotogramas táticos: o cinema marginal e suas táticas frente às formas dominantes de pensamento. In: NASCIMENTO, Alcides; VAINFAS, Ronaldo (Orgs.). História e Historiografia. Recife: Edições Bagaço, 2006. p. 97-118.

- Artistas diaspóricos, literatos desviados: fanzines, cultura ordinária e literatura menor. In: ADAD, Shara Jane Holanda Costa; BRANDIM, Ana Cristina Meneses de Sousa; RANGEL, Maria do Socorro (Orgs.). Entre línguas: movimento e mistura de saberes. Fortaleza: Edições UFC, 2008. p. 61-75.

. Rupturas instauradoras e funcionamento social da imagem no Brasil contemporâneo. In: CASTELO BRANCO, Edwar de Alencar (Org.). História, Cinema e outras imagens juvenis. Teresina: EDUFPI, 2009. p. 7-10.

CARDOSO, Ciro Flamarion. História e Paradigmas Rivais. In: CARDOSO, Ciro Flamarion; VAINFAS, Ronaldo (Orgs.). Domínios da História: Ensaios de Teoria e Metodologia. Rio de Janeiro: Elsevier, 1997. p. 1-23.

CERTEAU, Michel de. A invenção do cotidiano: 1. Artes de fazer. Tradução: Ephraim Ferreira Alves. Petrópolis: Vozes, 1994.

. A operação historiográfica. In: CERTEAU, Michel de. A escrita da história.

Tradução: Maria de Lourdes Menezes. 2. ed. Rio de Janeiro: Forense Universitária, 2000.

CHAVES, Reginaldo Sousa. Flanar pela Cidade-Sucata compondo uma estética da existência: Roberto Piva e seu devir literário experimental. 2010. Dissertação (Mestrado em História) - Universidade Federal do Piauí - Teresina.

COELHO, Frederico. Eu, brasileiro, confesso minha culpa e meu pecado: cultura marginal no Brasil das décadas de 1960 e 1970. Rio de Janeiro: Civilização Brasileira, 2010.

CORDEIRO JR, Barreto. Tropicalismo: fator de alienação ou de revisão crítica da realidade social? Teresina: Academia Piauiense de Letras, 1989.

COUTO FILHO, Durvalino. Os caçadores de prosódias. Teresina: Projeto Petrônio Portela, 1994. 
DIAS, Claudete Maria Miranda. O Piauí que o Brasil não Vê: História, Arte e Cultura. In: SANTANA, R. N. Monteiro de (Org.). Apontamentos para a história cultural do Piauí. Teresina: FUNDAPI, 2003. p. 215-231.

FAVARETTO, Celso. Tropicália: alegoria, alegria. São Paulo: Kairos, 1979.

GALVÃO, Demetrios Gomes. A fabricação de Teresinas: subjetividades e imagens fotográficas na experiência teresinense do Salão Municipal de Fotografia. 2008. Dissertação (Mestrado em História) - Universidade Federal do Piauí - Teresina.

- Ressonâncias no meio do caminho e/ou no caminho do meio: a poética infame dos fanzines. In: MUNIZ, Cellina Rodrigues (Org.). Fanzines: Autoria, Subjetividade e Invenção de Si. Fortaleza: Edições UFC, 2010. p. 81-97.

HALL, Stuart. A identidade cultural na pós-modernidade. Rio de Janeiro: DP\&A, 1999.

KRUEL, Kenard. Torquato Neto ou A Carne Seca é Servida. 2. ed. amp. Teresina: Zodíaco, 2008.

LIMA, Frederico Osanan Amorim. Curto-circuitos na sociedade disciplinar: super-8 e contestação juvenil em Teresina (1972-1985). 2007. Dissertação (Mestrado em História) Universidade Federal do Piauí - Teresina:

MACHADO, Paulo. Geração Pós-69. Apud: LIMA, Luiz Romero. Presença da literatura piauiense. 3. ed. Teresina: 2003. p. 234-236.

NERY, Emília Saraiva. Devires na música popular brasileira: Raul Seixas e as tensões culturais do Brasil nos anos 1970. 2008. Dissertação (Mestrado em História) - Universidade Federal do Piauí - Teresina:

PIRES, André Monteiro Guimarães Dias. A ruptura do escorpião: ensaio sobre Torquato Neto e o mito da marginalidade. São Paulo: Grupo Editorial Cone Sul, 1999.

QUEIROZ, Teresinha. A cultura brasileira no limiar do século XXI. In: EUGÊNIO, João Kennedy (Org.). Histórias de vário feitio e circunstância. Teresina: Instituto Dom Barreto, 2001. p. 302-319.

. Historiografia piauiense. In: Do singular ao plural. Recife: Edições Bagaço, 2006. p. $151-160$.

REIS, Flávio. Cenas marginais: fragmentos de Glauber, Sganzerla e Bressane. São Luís: Litograf, 2005.

SPINK, Mary Jane P.; FREZZA, Rose Mary. Práticas discursivas e produção de sentidos: a perspectiva da Psicologia Social. In: SPINK, Mary Jane P. (Org.). Práticas discursivas e 
produção de sentidos no cotidiano: aproximações teóricas e metodológicas. São Paulo: Cortez, 1999. p. 17-39.

TAVARES, Zózimo. Sociedade dos poetas trágicos: vida e obra de 10 poetas piauienses que morreram jovens. Teresina: Gráfica do Povo, 2004.

VELOSO, Caetano. Verdade Tropical. São Paulo: Companhia das Letras, 1997. 